\title{
Evaluation of market demand for a specific product
}

\author{
Zuzana Rowland ${ }^{1}$, Jiři Kučera ${ }^{2,}$, and Leona Martínková ${ }^{1}$ \\ ${ }^{1}$ Institute of Technology and Business in České Budějovice, School of Expertness and Valuation, \\ Okružní 517/10, 37001 České Budejovice, Czech Republic \\ ${ }^{2}$ University of Žilina, The Faculty of Operation and Economics of Transport and Communications, \\ Department of Economics, Univerzitná 8215/1, 01026 Žilina, Slovakia.
}

\begin{abstract}
The aim of this paper was to evaluate the demand for mobile phones in the world at the time of the coronavirus pandemic and to predict future development up until the end of 2022. During the covid-19 pandemic, markets in all sectors were subdued due to limited production and sales. As the production of chips for electronics was one of the deeply affected areas in terms of production slowdown, along with the rapid purchase of electronics at the beginning of the pandemic, there was also a slowdown in sales. The method of describing time series and calculation using linear regression is used. In this work, it is found that the decline in demand for mobile phones was caused by a global pandemic and consumers' uncertainty in maintaining their jobs. Overall, during the covid-19 pandemic, we saw a drop in the number of mobile phone units sold by more than 40,000 . Furthermore, it was found that the entire mobile phone market is clearly recovering after the coronavirus crisis.
\end{abstract}

Keywords: demand, coronavirus, market, smartphones

\section{Introduction}

The 2019 coronavirus pandemic (COVID-19) according to Majerova and Fernandes [1] disrupted supply chains, exposing gaps and vulnerabilities. Retailers are challenged to address the risks and organize themselves to fit into a new scenario [2]. This global epidemic has created a volatile environment for supply chains, raised the question of market survival and forced companies to rethink resilient strategies to be adopted for the post-pandemic situation in order to mitigate the long-term effects of the virus [3]. These articles point to the issue of market functioning in the current coronavirus era [4-6]. The decisive factor for building interorganizational relations is the interdependence between members. When one of the members does not fully oversee its management, there is a mutual dependence [7]. We need to think about what features the market interpretation allows us to do. Here we also use duality theory, for example for the introduction of demand constraints or the provision of services that result in artificial pricing behavior and economic losses. To overcome these problems, we examine market incentive mechanisms that use supply. We introduce product representation for the supply chain and show that this representation allows us to determine the minimum supply and these subsequently activate the markets. These results then provide

* Corresponding author: kuceraj@mail.vstecb.cz 
guidance for the formulation of a supervisory committee that rewards stakeholders who support market transactions. Tominac and Zavala [8] state that customer demand for a product is closely linked to their likelihood of purchase. This probability is determined by their purchase benefit, which depends on the reference price, the selling price and the risk factors. According to their asymmetric perception based on the difference between the reference and the selling price, customers in the market are divided into three categories. Namely, aversion to losses, search for profit and neutrality to losses. Zhao et al. [9] consider the mobile phone market to be very dynamic. It is constantly undergoing innovations and a great competitive environment forces manufacturers to come up with more sophisticated sales methods. In the second quarter of 2019, sales of mobile phones fell by $1.7 \%$. Mobile phone sales grew only in China and Brazil [10]. The aim of this paper is to evaluate the demand for mobile phones in the world during the coronavirus pandemic and predict future developments up until the end of 2022. To meet the aim of the paper, the following research questions were set out:

RQ1: How was the demand for mobile phones developing in the world 5 years before the coronavirus pandemic?

RQ2: How has the demand for mobile phones in the world changed since the beginning of the coronavirus pandemic?

RQ3: What is the estimate of the price development of phones in the period from 6/2021 to $12 / 2022$.

Realizing synergies is a decision-making problem. The aim is to reduce the time and effort required to gather information and assess synergies by industry subjects and intermediary stakeholders. Indicators represent the technical feasibility, economic viability and environmental benefits of a potential resource exchange [11]. However, determining a match between supply and demand and assessing its economic and environmental benefits remains a challenge in view of potentially conflicting objectives. Included are direct waste to resources, indirect waste to resources, by products to resources of higher value and waste to new materials. The cost-benefit analysis, together with the necessary environmental impact assessment, can be used to evaluate and optimize ecological networks so that they are commercially viable [12]. The characteristics of the spot electricity market and a financial model based on the net present value indicator are also discussed. The current document presented a technical and economic assessment of five thermal energy storage technologies in the integration of concentrated solar power system production into the SPOT electricity market [13]. For stated preference methods, products with certain attributes are identified or placed on experimental "markets!" to give respondents preferences for the product considered as a combination of attributes. Revealed preferences can be obtained from actual purchases, such as past market data or experimental procedures. Both methods have their advantages and disadvantages. For mobile phones, market shares were influenced by features related to functionality and appearance, such as battery life and unused appearance. At the same time, full repairability has proved to be less desirable than the ability to replace critical parts [14]. A four-part questionnaire was designed to analyze the potential demand for eggs produced companies that practice social farming. However, according to the respondents, two factors appear to be decisive for ensuring the future development of social farming, namely an adequate certification system and proper communication on the added value of social farming products [15]. The analysis is based on annual data on energy production until 2019 from BP public limited company. Ember's data on the energy sector for the first half of 2020 for a subset of countries, representing about threequarters of global energy production, are shown in Figure $1 \mathrm{~b}$ for comparison. The data on $\mathrm{CO} 2$ emissions for the period 2011 to 2018 comes from International Energy Agency and data for 2019 is derived from production data contained in the BP public limited company data set assuming constant emission factors by fuel. Uncertainties about the outlook for the near future are considerable, but it is possible that $\mathrm{CO} 2$ emissions from the energy sector will not return to 
the level of 2018. Various policy instruments could effectively support the accelerated reduction of emissions over the next few years [16]. Impact of COVID-19 and national restrictions on vegetable prices with evidence from wholesale markets. Price data and market information were collected from the National Database of Agricultural Product Prices by method of web-browsing [17]. Influence of COVID-19 on real estate prices. Using a revised method of differences with nonparametric smoothing, which more intensively controls the unobservable, we are able to model the effects of the outbreak on real estate prices as a continuous time function. The results show that after the outbreak of the Honolulu epidemic, it is the only place where real estate prices have fallen, with the largest decline approaching $6.69 \%$ in April 2020. For the other four areas recording real estate prices, the largest increase was $9.97 \%$ in Santa Clara, followed by Irvine with a growth of $5.80 \%$. Houston and Des Moines have also generally seen an increase in property prices [18]. For our paper we will also utilize the description of time series and also calculation using linear regression.

\section{Data and methods}

\subsection{Data}

We collected the utilized data from the website [19], where we searched for an article containing the global share of the smartphone market listing quarterly data from 2014 to 2021 . We compared the smartphone brands Apple, Huawei, Xiaomi and Samsung. First of all, we will deal with the question of how the demand for mobile phones in the world has been developing 5 years before the coronavirus pandemic outbreak. For this, we will compare the quarterly data of selected smartphone brands from 2015 to March 2021, which we can see in Table 1.

Table 1. Quarterly demand in mil. of pieces 2015-March 2021

\begin{tabular}{|c|c|c|c|c|c|}
\hline Year & Apple & Huawei & Xiaomi & Samsung & Total \\
\hline 31.03 .2015 & 61.2 & 17.3 & 15.3 & 83.2 & 177 \\
\hline 30.06 .2015 & 47.5 & 3.5 & 19 & 74.5 & 144.5 \\
\hline 30.09 .2015 & 48 & 27.4 & 18.2 & 84 & 177.6 \\
\hline 31.12 .2015 & 74.8 & 32.6 & 18 & 81.3 & 206.7 \\
\hline 31.03 .2016 & 51.2 & 28.4 & 14.5 & 78.6 & 172.7 \\
\hline 30.06 .2016 & 40.4 & 32 & 14.5 & 77 & 163.9 \\
\hline 30.09 .2016 & 45.5 & 33.6 & 16 & 76 & 171.1 \\
\hline 31.12 .2016 & 78.3 & 44.9 & 15.8 & 77.5 & 216.5 \\
\hline 31.03 .2017 & 50.8 & 34.6 & 13.4 & 80 & 178.8 \\
\hline 30.06 .2017 & 41 & 38.5 & 23.1 & 80.4 & 183 \\
\hline 30.09 .2017 & 46.7 & 39.1 & 28.5 & 83.3 & 197.6 \\
\hline 31.12 .2017 & 77.3 & 41 & 31 & 74.4 & 223.7 \\
\hline 31.03 .2018 & 52.2 & 39.3 & 28.1 & 78.2 & 197.8 \\
\hline 30.06 .2018 & 41.3 & 54.2 & 32 & 71.5 & 199 \\
\hline 30.09 .2018 & 46.9 & 52 & 33.3 & 72.3 & 204.5 \\
\hline 31.12 .2018 & 65.9 & 59.7 & 25.6 & 69.8 & 221 \\
\hline 31.03 .2019 & 42 & 59.1 & 27.8 & 72 & 200.9 \\
\hline
\end{tabular}




\begin{tabular}{|c|c|c|c|c|c|}
\hline 30.06 .2019 & 36.5 & 56.6 & 32.3 & 76.3 & 201.7 \\
\hline 30.09 .2019 & 44.8 & 66.8 & 31.7 & 78.2 & 221.5 \\
\hline 31.12 .2019 & 72.3 & 56.2 & 32.9 & 70.4 & 231.8 \\
\hline 31.03 .2020 & 40 & 49 & 29.7 & 58.6 & 177.3 \\
\hline 30.06 .2020 & 37.5 & 54.8 & 26.5 & 54.2 & 173 \\
\hline 30.09 .2020 & 41.7 & 50.9 & 46.2 & 80.4 & 219.2 \\
\hline 31.12 .2020 & 81.9 & 33 & 43 & 62.5 & 220.4 \\
\hline 31.03 .2021 & 59.5 & 15 & 48.5 & 76.6 & 199.6 \\
\hline
\end{tabular}

Source: [19].

According to Table No. 1, it is clear that the biggest players in the smartphone market are Apple and Samsung. Every year, however, the total number of units sold shows that the largest sales of mobile phones are always in the last quarter of each year. Overall, it is also evident that mobile phone sales are rising worldwide.

\subsection{Methods}

In the second part of the data comparison, we compare the demand before the coronavirus pandemic, i.e. the quarterly data from March 31, 2018 to March 31, 2019, with the demand during the pandemic from March 31, 2020 to March 31, 2021.

Our next step is to use simple linear regression to calculate the assumed prediction. Here we will use the overall calculation of quarterly data of all selected smartphone brands from 2015 to March 2021 and then calculate the estimate up until December 2022.

Last but not least, we will use the method of exponential alignment of the time series to smooth the short-term prediction of time series. This will utilize all the quarterly series from a given time period plus added prediction.

\section{Results}

To compare the demand before the coronavirus pandemic, i.e. quarterly data from March 31, 2018 to March 31, 2019, with the demand during the pandemic, i.e. quarterly data from March 31, 2020 to March 31, 2021. For this comparison, we used a line graph that shows the data with a blue line before the pandemic and then an orange line for data for the period during Covid-19; see Figure 1. 




Figure 1. Quarterly data before and durnng Covid-1y During COVID Source: Own processing.

Figure 1 shows that in the period from March 31, 2018 to March 31, 2019, the trend in the number of units of mobile phones sold was usual with a gradual increase in the number of units sold during the year, with highs in the last quarter. During 2020, when the Covid-19 pandemic began, the largest increase in cell phone sales was recorded as anti-epidemiological measures were introduced. With the duration of these measures, the number of units sold remained at the upper end of 2020.

Using a simple linear regression to calculate the assumed prediction, we used the overall calculation of quarterly data of all selected smartphone brands from 2015 to March 2021 and then calculated the estimate up to December 2022. First, we used scatter plot in figure 2 to show the total values from 2015 to March 2021.



Figure 2. Total values from 2015 to March 2021

Source: Own processing. 
Furthermore, when calculating simple linear regression, we used a line graph in figure 3 with a prediction from June 2021 to December 2022.

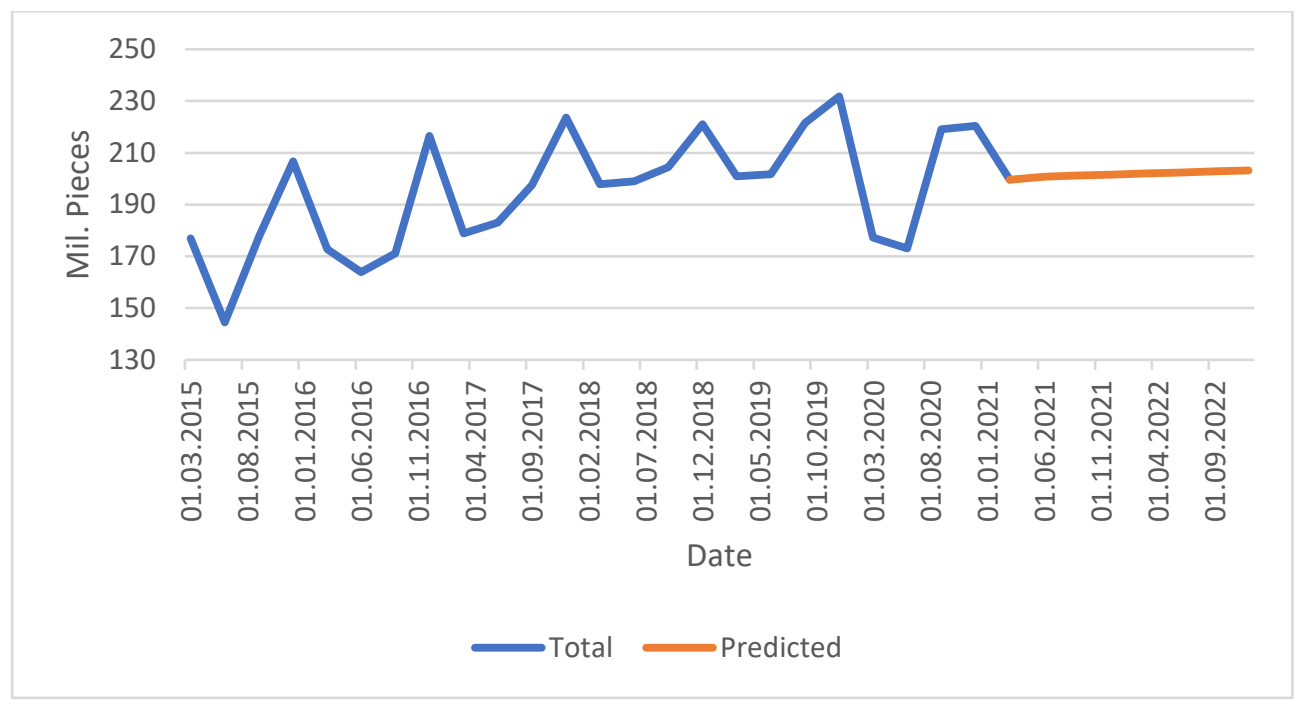

Figure 3. Prediction from June 2021 to December 2022

Source: Own processing.

From Figure 3 it is evident that in the period from March 31, 2021 to Decembed 2022, a gradual increase in the number of ordered pieces can be expected throughout the year 2022 .

Finally, we used the method of exponential alignment of time series to smoothen the short-term prediction of time series. We used all quarterly series from the given time period here plus added prediction. To display this data, we again used a simple line graph in figure 4 , which shows the total value of the blue line and the estimated prediction of the orange line.



Figure 4. Total quarterly data and smoothened forecast

Source: Own processing. 
Finally, the method of exponential alignment of time series was used to refine the prediction using linear regression to smooth the short-term prediction of time series. Based on the achieved results, it is evident that in 2022 the trend in the number of sold pieces of mobile phones from the period before the covid-19 pandemic will be copied again.

\section{Discussion}

Based on the obtained results, we are able to answer the determined research questions:

How has the demand for mobile phones been developing in the world 5 years before the coronavirus pandemic? Demand was usually the highest in the 4th quarter, i.e. always at the end of the year. The end of the year means the most profitable time of the year for most retailers, because people buy Christmas presents. This also applies to the smartphone market, as electronics companies present smartphones as an ideal gift for Christmas. For example, Apple introduces new models mostly at the end of the year.

How has the demand for mobile phones in the world changed since the beginning of the coronavirus pandemic? According to the obtained results, it can be seen that at the beginning of the coronavirus pandemic, people saved money. It is possible that the reason for saving was fear and uncertainty in maintaining jobs. However, as we can see in figure 2, the demand for mobile phones increased again at the end of the year. The increase in demand may have been due to the upcoming Christmas holidays or the stabilization of fear from the coronavirus pandemic. About 360 million smartphones were sold in the third quarter, which is only 4 percent less than last year. This growth may be an interesting indicator for the marketing industry in the coming years.

What is the estimate of the price developments of mobile phones in the period from June 2021 to December 2022? Using exponential time series alignment to smoothen the shortterm time series prediction, it has been shown that the entire smartphone market is clearly recovering from the coronavirus crisis. According to this data, it can be assumed that the price development of phones in the coming years will be similar to previous years.

\section{Conclusion}

The aim of the paper was to assess the demand for mobile phones in the world during the coronavirus pandemic and predict future developments up until the end of 2022. Using determined research questions and quarterly data [19] from 2014 to 2021, we compared the demand for Apple, Huawei, Samsung and Xiaomi. Among other things, we found that while sales of Samsung smartphones stagnated, Huawei and Apple phones experienced a year-onyear decline. By comparing the pre-coronavirus pandemic demand using a simple linear regression between March 31, 2018 and March 31, 2019, and then between March 31, 2020 and March 31, 2021, the following was found: before the coronavirus pandemic, almost always in the 4th quarter, demand was highest probably due to the Christmas holidays. During the coronavirus pandemic, the smartphone market declined slightly, but demand increased again in the fourth quarter. Furthermore, using the method of exponential adjustment of the time series for smoothing the short-term prediction of time series, it is assumed that the price development of mobile phones will be similar to previous years. As we have already summarized in the discussion of the results, the decline in demand for mobile phones was caused by a global pandemic and uncertainty of consumers maintaining their jobs. If the situation regarding the coronavirus crisis stabilizes and the smartphone market, and with it the economy as a whole, picks up activity as part of the recovery, mobile phone manufacturers do not need to feel threatened. 


\section{References}

1. J. Majerova, C. Fernandes, How to make Phoenix to arise from the ashes: Brand loyalty as a prospective pillar of branding in tourism after crisis COVID-19. Littera Scripta, 13(2), 49-58 (2020)

2. P. Pardál, R. Dias, P. Šuleř, N. Teixeira, T. Krulický, Integration in Central European capital markets in the context of the global COVID-19 pandemic. Equilibrium Quarterly Journal of Economics and Economic Policy, 15(4), 627-650 (2020)

3. J. Horák, K. Mlsová, V. Machová, Impact of the coronavirus pandemic on the tertiary sector. Littera Scripta, 14(1), 28-39 (2021)

4. M. Sharma, S. Luthra, S. Joshi, A. Kumar, Accelerating retail supply chain performance against pandemic disruption: adopting resilient strategies to mitigate the long-term effects. Journal of Enterprise Information Management (2021)

5. M. Sharma, S. Luthra, S. Joshi, A. Kumar, Developing a framework for enhancing survivability of sustainable supply chains during and post-COVID-19 pandemic. International Journal of Logistics Research and Applications (2020)

6. R. Dias, N. Teixeira, V. Machová, P. Pardál, J. Horák, M. Vochozka, Random walks and market efficiency tests: Evidence on US, Chinese and European capital markets within the context of the global Covid-19 pandemic. Oeconomia Copernicana, 11(4), 585-608 (2020)

7. A. Kamalaldin, L. Linde, D. Sjödin, V. Parida, Transforming provider-customer relationships in digital servitization: A relational view on digitalisation. Industrial Marketing Management, 89, 306-325 (2020)

8. P. A. Tominac, V. M. Zavala, Economic properties of multi-product supply chains. Computers \& Chemical Engineering, 145 (2021)

9. N. Zhao, Q. Wang, P. Cao, J. Wu, Pricing decisions with reference price effect and risk preference customers. International Transactions in Operational Research, 28(4), 20812109 (2019)

10. M. Framingham, Smartphone shipments decline $2.3 \%$ in the second quarter on continued challenges across most major regions, According to IDC [online]. Available at: https://www.businesswire.com/news/home/20190731005812/en/Smartphone-

Shipments-Decline-2.3-in-the-Second-Quarter-on-Continued-Challenges-Across-MostMajor-Regions-According-to-IDC (2019)

11. L. Kosmol, M. Maiwald, C.Pieper, J. Plötz, T. Schmidt, An indicator-based method supporting assessment and decision-making of potential by-product exchanges in industrial symbiosis. Journal of Cleaner Production, 289 (2021)

12. S. Bin, Y. Zhiquan, L.S.C. Jonathan, D.K. Jiewei, D. Kurle, F. Cerdas, C. Herrmann, A big data analytics approach to develop industrial symbioses in large cities Procedia CIRP. The 22nd CIRP Conference on Life Cycle Engineering, 29, 450-455 (2015)

13. I. Khamlich, K. Zeng, G. Flamant, J. Baeyens, C. Z. Zou, J. Li, X. Y. Yang, X. He, Q. C. Liu, H. P. Yang, Q. Yang, H. P. Chen, Technical and economic assessment of thermal energy storage in concentrated solar power plants within a spot electricity market. Renewable and Sustainable Energy Reviews, 139 (2021)

14. A. D. Hunka, M. Linder, S. Habibi, Determinants of consumer demand for circular economy products. A case for reuse and remanufacturing for sustainable development. Business Strategy and the Environment, 30, 535-550 (2021) 
15. T. Tempesta, D. Vecchiato, F. Nassivera, M. Bugatti, B. Torquati, Consumers demand for social farming products: An analysis with discrete choice experiments. Sustainability, 11(23), (2019)

16. Ch. Bertram, G. Luderer, F. Creutzig, N. Bauer, F. Ueckerdt, A. Malik, O. Edenhofer, COVID-19-induced low power demand and market forces starkly reduce $\mathrm{CO}_{2}$ emissions. Nature Climate Change, 11(3), (2021)

17. J. Ruan, Q. Cai, S. Jin, Impact of COVID"19 and nationwide lockdowns on vegetable prices: Evidence from wholesale markets in China. American Journal of Agricultural Economics, 103(5), 1574-1594 (2021)

18. B. Wang, How does COVID-19 affect house prices? A cross-city analysis. Journal of Risk and Financial Management, 14(2), (2021)

19. Counterpoint, Global Smartphone Market Share: By Quarter. Counterpoint USA: Counterpoint team [online]. Available at: https://www.counterpointresearch.com/global-smartphone-share/ (2021) 